So why should a dentist bother to deliver

care to many patients in a day, when

he/she could target and see fewer of those

with little need for care but are prepared

to pay for non-health related activities?

\title{
A Win Win Scenario
}

There is much scepticism, mistrust and insecurity surrounding the government's future proposals for dentistry and the profession. This is understandable following the last 15 years of dentistry in the UK.

In the UK we are trail-blazers in terms of the delivery of health care. We just have to look at our health services since Aneurin Bevan's original model of care. Even with its present shortcomings we have to acknowledge the NHS, as a service, has been the envy of the world. Its egalitarian and equitable principles appeal to all regardless of status because it is fundamentally humanitarian.

With devolution each of the countries making up the UK is responsible for the development of health services. In England the tradition of the NHS principle is being fostered. This was recognised and reported in the National Audit Office report Reforming NHS Dentistry: Ensuring effective management of risks. I quote:

"No country attempts to provide comprehensive care for all or operates a system similar to that proposed by the Department, underlining the risks that will need effective management if the new system is to prove value for money".

A new system which is value for money - we must accept that everyone wants a fair day's pay for a fair day's work. With financial insecurity an issue, changing rhetoric to reality is not always smooth as was the original experience pre 1948 and the NHS. The future is about being fair to all involved. We are looking to re-evaluate the optimum day for a dentist (getting off the treadmill) and also we want to be rewarded for professional activity at levels appropriate for comparable professionals.

Focusing on the optimal day for the dentist, is the optimal day about being responsible for $10,20,30$ or 40 patients? How much time does a dentist need to care for a family of four for check-ups, a patient for a filling and another for a denture try? If the family is a healthy low risk family, the filling an adhesive composite and a satisfactory denture try; then I would say less than an hour.
Capacity within a dental practice will be dependent on many issues. These include service provision issues such as the organisational mindset of the dentist - to use or not to use PCDs, the diagnostic mindset of the dentist - to 'extend to prevent' or 'watch and wait', the preventive mindset of the dentist. Of course the demands placed on services must be considered in the dental market-place. Supply induced demand may have a negative effect on oral health outcomes which could be viewed as poor value for money to the public purse.

So why should a dentist bother to deliver care to many patients in a day, when he/she could target and see fewer of those with little need for care but who are prepared to pay for non-health related activities? If it is maximum financial return for minimal effort that motivates us as dentists then it would make sense for expansion of the latter.

The bottom line in dentistry is for us to decide which receives greater weight - health needs or patient demands and organise services accordingly. The only way to assess this is to observe national oral health outcomes.

Most dentists have a desire to do things correctly, based on evidence. Value for money applies to NHS and private dentistry. During times of change, fear of the unknown is not uncommon. We must acknowledge the vast improvements in oral health that have occurred in affluent populations and our challenge is to reduce the social oral health divide.

There is an opportunity to develop a balanced approach to oral health care where all three stakeholders win; dentists receiving a fair day's pay, patients receiving a fair day's work from dentists and government receiving first class health statistics for the whole population. 